\title{
FILSAFAT ILMU PENGETAHUAN
}

* Ismail Marzuki \# Siswandy \# M. Iqbal \#Andi Muhammad Reza \# I Putu Artawan \# Arsad Ely \#irfan Saputra \# Musmulyadi 


\section{Filsafat Ilmu Pengetahuan}

By

\# Ismail Marzuki \# Siswandy \# M. Iqbal \#

\# Andi Muhammad Reza \# I Putu Artawan \# Arsad Ely \#

\# Irfan Saputra \# Musmuliadi \#

Makassar

2021 


\section{Filsafat Ilmu Pengetahuan}

RR.TI0000-04-2021

Penulis

Dr. Ismail Marzuki, M.Si,

Siswandy, S.Kom., M.

Iqbal, ST.,

Andi Muhammad Reza, ST,

Ir. I Putu

Artawan, ST.,

Arsad Ely, ST,

Irfan Saputra,

Ir.Musmuliyadi ST, IPM.

Editor Dr. Muhammad Asdar, S. Ksi., M.Si

Dr. Sry Gusti. ST., MT

Desain Grafis Alif Syahbana Bahar

Layout ZulFahmi Noor, ST

Diterbitkan oleh Fakultas Teknik Universitas Fajar

Jl. Prof. Abdurrahman Basalamah No. 101

Makassar 90231

Tlp. 082194130545

Fax. (0411) 441119

e-mail: ft@unifa.ac.id

Hak cipta dilindungi undang-undang pada penulis

ISBN 978-602-51509-8-2

Dicetak oleh team penerbit Fakultas Teknik Universitas Fajar 


\section{Kata Pengantar}

Rasa syukur yang tinggi dicurahkan atas kehadirat Allah SWT yang telah memberi kesehatan, kekuatan, kesempatan dan kemampuan untuk dapat menyelesaikan naskah penulisan buku berjudul: Filsafat Ilmu Pengetahuan. Buku ini adalah karya bersama mahasiswa program Pascasarjana Magister Rekayasa Infrastruktur dan Lingkungan Universitas Fajar dalam bimbingan dan arahan dosen pengampuh matakuliah filsafat.

Penerbitan buku ini didasarkan pada renungan dan evaluasi penugasanpenugasan yang diberikan mahasiswa dalam 3 tahun terakhir dalam matakuliah filsafat tersebut yang seolah bahwa tugas-tugas mahasiswa tidak begitu memberi arti dalam aspek pengembangan ilmu dan peningkatan wawasan berkehidupan dan dinamika sebagai makhluk sosial yang ada di belahan bumi ini. Wawasan keilmuan jangka panjang dan review kebelakang atas dinamika perkembangan pengetahuan manusia, maka dilakukan inovasi dan kreativitas kami dalam komunitas kecil matakuliah filsafat untuk menghasilkan setitik dokumen hasil pembelajaran dalam bentuk buku. Setetes harapan atas penerbitan buku ini agar dapat menjadi bahan bacaan generasi milenial yang notabene oleh banyak kalangan menjuluki komunitas mereka sebagai generasi $Y$ atau generasi "Echo Boomer" yang lahir sebagai turunan dari Gen-X dan mengalami booming di awal abad ke 20.

Susunan buku ini tentu masih sangat sederhana dan bukan tidak mungkin merupakan buku dengan kualitas rendah dalam hal narasi-narasi yang tersampaikan termasuk dalam hal pengutipan, namun satu keyakinan kami bahwa dalam buku ini tetap memberi pencerahan walau hanya segenggam manfaat, khususnya bagi mahasiswa kami untuk membuat mereka terbiasa dan sebagai titik awal untuk dapat berselancar dalam suatu penulisan karya-karya ilmiah.

Salam literasi untuk kita semua, semoga dengan kreativitas dan inovasi serta semangat dalam menulis dapat menjadi titik awal untuk menumbuhkan semangat dalam berkarya. Kepada teman-teman dosen tidak terkecuali diri 
Saya, bahwa yang kami lakukan semata untuk menumbuhkan semangat yang bukan tidak mungkin juga dapat diikuti oleh dosen-dosen yang lainnya. Sehingga tugas-tugas mahasiswa dapat di runut kebelakang dalam bentuk buku, harapan dari kreativitas ini adalah tugas-tugas mahasiswa tidak hanya sekedar memenuhi kewajiban matakuliah, tetapi dapat menjadi karya yang terdokumentasi dan dapat dikenang sepanjang masa.

Terima kasih untuk semua, para mahasiswaku atas segala usaha dan kerja kerasnya sehingga karya-karya kalian dapat terdokumentasi dalam buku ini, semoga kalian tetap dapat membaca kembali dan mereviewnya, sehingga akan Anda temukan titik dan sisi kelemahan dari karya-karya Anda, Aamiin...... Aamiin..... Aamiin.

Tim Penulis,

Ismail Marzuki, dkk 


\section{Daftar Isi}

Halaman Sampul_i

Kata Pengantar_ii

Daftar Isi_iv

Bab I Potret Filsafat Dulu dan Kini_1

1.1 Pendahuluan _1

1.2 Definisi Filsafat dari Aspek Bahasa _ 2

1.3 Hakikat dan Filosofi Filsafat_4

1.4 Konsep dan Teori Lahirnya Filsafat _ 7

1.5 Tahapan dan Sistematika Filsafat_8

1.6 Sejarah Timbulnya Filsafat_12

1.7 Sifat Universalisme Filsafat_18

Bab II Pandangan Ilmu Pngetahuan Terhadap Filsafat_21

2.1 Pertentangan antara Mitos dan Logos_21

2.2 Karakteristik Filsafat_26

2.3 Komunalisme Filsafat_29

2.4 Pengantar Ontologi Dalam Filsafat_32

2.5 Pengantar Epistemologi_37

Bab III Pandangan Filsafat terhadap Fenomena Alam_39

3.1 Pengaruh Kesusastraan terhadap Filsafat_39

3.2 Filsafat Ilmu_42

3.3 Filsafat versus Alam Empiris _47

3.4 Korelasi Filsafat terhadap Agama_49

3.5 Komunisme dalam Berfilsafat_52

Bab IV Eksistensi Manusia sebagai Pencetus Ilmu _57

4.1 Pendahuluan_57

4.2 Esensi berpikir, bertindak Logis, Sistematis dan Radikal _63

4.3 Manusia antara ada dan Tiada_69

4.4 Sejak Kapan Manusia mengenal Pengetahuan_75

4.5 Siklus Ilmu Pengetahuan_80

Bab V Pandangan Filsafat terhadap Pendidikan Kebangsaan Berbasis Tauhid_91 
5.1 Pendahuluan_91

5.2 Pendidikan Kebangsaan dalam Persfektif Kebudayaan _93

5.3 Pendidikan Kebangsaan Berbasis Islam_98

5.4 Fundamental Pendidikan Kebangsaan Berbasis Tauhid_104

Bab VI Pandangan Filsafat dalam Rasionalisme Manusia _109

6.1 Rasionalisme Filsafat_109

6.2 Rasionalisme Descartes dan Implikasinya _114

6.3 Konsep Rasionalisme _116

6.4 Rasionalisme dan Agama _117

Bab VII Filsafat dan Paradigma Sains Masa Kini_123

7.1 Filsafat dan Revolusi Sains _123

7.2 Paradigma Modern_128

7.3 Intuisi dan Metode Ilmiah_129

7.4 Transendentak dan Kohesi_137

7.5 Paradigma Filsafat Sains Thomas Kuhn_139

Bab VIII Ilmu Pengetahuan, Teori dan Nilai dalam Filsafat_143

8.1 Filsafat dalam Perspektif Pendidikan Islam_143

8.2 Aspek Ontologi_151

8.3 Aspek Aksiologi_161

8.4 Contoh-contoh Ontologi, Epistemologi dan Aksiologi _163

Daftar Pustaka -165

Biodata Penulis_173

Sinopsis 



\section{Bab I \\ Potret Filsafat Dulu dan Kini}

\subsection{Pendahuluan}

Filsafat berkembang seiring dengan perubahan dan tuntutan hidup manusia serta telah melewati sejarah panjang. Filsafat adalah induk dari ilmu pengetahuan dan mulai berkembang pada abad kelima SM. Pada abad itu muncul gugatan mengenai kebenaran pengetahuan yang sudah berabad-abad diterima dengan sangat baik dan bersumber dari mitos dan mitologi. Abad kelima SM muncul para filsuf-filsuf pertama yang meragukan kebenaran mitos dan berusaha mencari kebenaran atas beberapa pertanyaan mendasar pada masa itu seperti: asal usul segala sesuatu, hakikat yang "Ada", alam semesta, kritisasi atas berbagai fenomena alam yang terjadi dan lain sebagainya (Mahawati et al., 2021).

Terdapat beberapa jawaban yang beraneka ragam terhadap fenomena yang terjadi dan yang utama bukan benar atau tidak benar atas jawaban yang ada, tetapi merupakan sikap kritis dalam menerima kebenaran atas penggunaan akal (rasio) sebagai sarana menemukan kebenaran pengetahuan. Beberapa filsuf alam yang muncul pada masa itu seperti Thales, Anaximes, Anaximander, Phytagoras, Herakleitos dan Sokrates, semuanya menyadari bahwa masih ada kemungkinan kesalahan dari pemikiran mereka. Filsuf-filsuf awal ini bukanlah sebagai pemilik kebenaran (pengetahuan, kebijaksanaan) tetapi pecinta kebijaksanaan. Penggunaan akal (rasio) untuk mencari kebenaran inilah merupakan 
babak baru dalam sejarah pemikiran manusia dimuka bumi. Abad kelima Sebelum Masehi sering disebut sebagai zaman logos yang menggantikan mitos dan mitologi yang menandai kelahiran filsafat (Wilujeng, 2014).

\subsection{Definisi Filsafat dari Aspek Bahasa}

Kata filsafat berasal dari bahasa Yunani philosophia; yakni kata philos berarti cinta dan Sophia berarti pengetahuan, hikmah atau kebenaran. Berdasarkan definisi etimologi, kata filsafat berarti "cinta terhadap pengetahuan atau kebijaksanaan". Definisi menurut bahasa tersebut dapat ditegaskan bahwa orang yang berfilsafat cenderung cinta terhadap ilmu dan kebijaksanaan atau selalu ingin mengetahui hakikat tentang sesuatu, karena filsafat pada intinya adalah upaya untuk mencurahkan seluruh pemikiran secara kontemplatif dan spekulatif untuk mencari sebuah kebenaran atau hakikat tentang sesuatu yang ada.

Bahasa lain tentang filsafat dikenal dengan sebutan philosophy (Inggris), philosophie (Prancis dan Belanda), filosofi, wijsbegeerte (Belanda), philosophia (Latin). Kata filsafat diambil dari bahasa Arab yaitu falsafah. Filsafat merupakan pemikiran secara sistematis. Kegiatan kefilsafatan ialah merenung atau dalam istilah lain kontemplasi. Perenungan dalam arti kefilsafatan adalah percobaan untuk menyusun suatu sistem pengetahuan yang rasional, yang memadai untuk memahami dunia tempat kita hidup, maupun untuk memahami diri kita sendiri. (Muchsin, 2004). Kata philosophia ini jika ditelisik dari asal-usulnya telah memiliki sejarah yang cukup panjang. Zaman Homerus (sekitar abad IX SM) dan zaman Hesiodos (sekitar tahun 700 SM), kata Sophia digunakan dalam arti kebijaksanaan dan punya kecakapan. Demikian pula zaman Horodatus (hidup tahun 485 SM) kata philosopher digunakan untuk arti mencintai kebenaran. Kemudian dilanjutkan oleh Herakleitos (540-480 SM) dan Phytagoras (580-500 SM). Ahli filsafat dalam sebutan Herakleitos adalah philosophos artinya manusia yang memiliki ilmu pengetahuan luas dari kecintaannya kepada kebenaran (Karim, 2014).

Pada masa Sofisme dan Socrates, philosophies ini diartikan begitu jelas sebagai suatu penguasaan secara sistematis terhadap ilmu pengetahuan teoritis. Philosophia adalah hasil dari philosophie sedangkan philosophos adalah orang yang melaksanakan philosophie. Dari kata inilah kemudian 
diambil menjadi kata-kata philosophia (Latin), philosophie (Perancis), philosophie (Belanda),philosophie (Jerman), philosophy (Inggris), falsafah (Arab) dan Filsafat (Indonesia) demikian pula bahasa-bahasa yang lain. Namun demikian dalam bahasa Arab sering digunakan sebutan al-Ulum al-Hikmah (ilmu hikmah) dan yang mengamalkannya disebut hakiem. Pengertian hakim dalam filsafat bersifat teoritis dan berbeda dengan hakim dalam pengertian biasa (sarjana hukum, pengabdi hukum) yang lebih bersifat praktis (M. Siti Ritaudin, 1015).

Harun Nasution berpendapat bahwa istilah filsafat berasal dari bahasa Arab, karena orang Arab lebih dahulu datang ke Nusantara dan sekaligus mempengaruhi bahasa Indonesia daripada orang Eropa yang menggunakan bahasa Inggris. Oleh karena itu beliau konsisten menggunakan kata filsafat, bukan filsafat. Buku-bukunya mengenai filsafat ditulis dengan falsafat, seperti filsafat agama dan falsafat dan mistisisme dalam Islam. (Amsal Bakhtiar, 1004). Meskipun istilah filsafat yang lebih tepat adalah falsafat yang berasal dari bahasa Arab, kata filsafat sebenarnya bisa diterima dalam bahasa Indonesia. Sebab, sebagian kata Arab yang diIndonesiakan mengalami perubahan dalam huruf vokalnya, seperti masjid menjadi mesjid, dan karomah menjadi keramat, karena itu perubahan huruf a menjadi i dalam falsafah bisa ditolerir. Lagi pula dalam kamus bahasa Indonesia, kata filsafat menunjukkan pengertian yang dimaksud, yaitu pengetahuan dan penyelidikan dengan akal budi mengenai hakikat segala yang ada, sebab, asal, dan hukumnya.

Filsafat menurut Kamus Besar Bahasa Indonesia berarti pengetahuan dan penyelidikan dengan akal budi mengenai hakikat segala yang ada, sebab, asal dan hukumnya. Filsafat dapat berarti juga teori yang mendasari alam pikiran atau suatu kegiatan atau juga ilmu yang berintikan logika, estetika, metafisika, dan epistemologi. Filsafat secara etimologi dan semantik merepresentasikan suatu nilai yang sangat fundamental yaitu "cinta" (love). Secara kamus, kata cinta sering disinonimkan dengan arti kata suka, senang, rindu, kasih sayang, hasrat yang tinggi dan mendalam. Cinta sebagai kata sifat, mempunyai kata kerja, yaitu mencintai (philen) atau bercinta (to loving) dan kata benda yaitu: pencinta (lover). Pencinta kebijaksanaan, kebenaran dan pengetahuan dalam arti yang hakiki ialah orang yang menjadikan pengetahuan sebagai tujuan hidupnya, mengabdikan dirinya kepada kebijaksanaan, kebenaran dan pengetahuan (Bahrun, 2013).

Sebagaimana halnya dengan definisi secara etimologi, maka secara terminologi atau istilah, rumusan definisi filsafat juga berbeda dan beragam di kalangan para ahli. Para filsuf merumuskan definisi filsafat sesuai dengan 
kecenderungan pemikiran kefilsafatan yang dimilikinya. Seorang Plato mengatakan bahwa: filsafat adalah pengetahuan yang berminat mencapai pengetahuan kebenaran yang asli. Sedangkan Aristoteles berpendapat bahwa filsafat adalah ilmu (pengetahuan) yang meliputi kebenaran yang terkandung didalamnya ilmu-ilmu metafisika, logika, retorika, etika, ekonomi, politik dan estetika. Lain halnya dengan Al Farabi yang berpandangan bahwa filsafat adalah ilmu (pengetahuan) tentang alam maujud bagaimana hakikat yang sebenarnya (Hanafi, 2018).

Filsuf di abad pertengahan, seperti Immanuel Kant (1714-1804) berpendapat bahwa filsafat adalah ilmu pengetahuan yang menjadi pangkal dari segala pengetahuan yang didalamnya tercakup empat persoalan, yakni: apakah yang dapat kita kerjakan (jawabannya metafisika), apakah yang seharusnya kita kerjakan (jawabannya etika), sampai dimanakah harapan kita (jawabannya agama) dan apakah yang dinamakan manusia (jawabannya antropologi).

Menurut Harold Titus tentang filsafat, bahwa filsafat adalah suatu sikap tentang hidup dan alam semesta, filsafat merupakan suatu metode berpikir reflektif dan penyelidikan rasional, filsafat adalah seperangkat masalah dan filsafat adalah suatu perangkat teori atau sistem pemikiran. Dari definisi yang diberikan Titus ini terlihat bahwa kajian filsafat itu cukup rumit, sehingga beliau memberikan definisi yang variatif sesuai dengan persoalan yang dihadapi. Dari sekian banyak definisi yang ada, maka salah satu rumusan yang dapat dijadikan rujukan adalah sebagaimana yang dikemukakan oleh Sidi Gazalba yang memberikan definisi filsafat sebagai: "berfikir secara mendalam, sistematis, radikal, dan universal dalam rangka mencari kebenaran, inti atau hakikat mengenai segala sesuatu yang ada". (Hanafi, 1018).

\subsection{Hakikat dan Filosofi Filsafat}

Agar dapat mengkaji lebih jauh tentang filsafat secara mendalam dan menyeluruh diperlukan pemahaman tentang hakikat filsafat. Hakikat filsafat yang dimaksud adalah makna sesungguhnya tentang filsafat itu sendiri. Hakikat merupakan istilah yang menjadi ciri khas filsafat. Hakikat adalah pemahaman atau hal yang paling mendasar. Jadi, filsafat tidak hanya berbicara tentang wujud atau materi bagaimana ilmu pengetahuan, tetapi berbicara makna yang terdapat di belakangnya. Filsafat adalah ilmu pengetahuan yang 
menyelidiki segala sesuatu yang ada secara mendalam dengan menggunakan akal sampai pada hakikatnya. Filsafat bukan mempersoalkan gejala-gejala atau fenomena tetapi yang dicari adalah hakikat dari suatu fenomena. Hakikat adalah suatu prinsip yang menyatakan "sesuatu" adalah "sesuatu" itu adanya. Filsafat adalah suatu usaha untuk mengetahui segala sesuatu. "Ada" merupakan implikasi dasar. Jadi segala sesuatu yang mempunyai kualitas tertentu pasti adalah "ada". Filsafat mempunyai tujuan untuk membicarakan keberadaan. Jadi filsafat membahas lapisan terakhir dari segala sesuatu atau membahas masalah yang paling mendasar (Siregar, 2016).

Filsafat berupaya mengkaji tentang masalah-masalah yang muncul dan berkaitan dengan segala sesuatu, baik yang sifatnya materi maupun immateri secara sungguh-sungguh guna menemukan hakikat sesuatu yang sebenarnya, mencari prinsip-prinsip kebenaran, serta berpikir secara rasional-logis, mendalam dan bebas sehingga dapat dimanfaatkan untuk membantu menyelesaikan masalah-masalah dalam kehidupan manusia. Hakikat filsafat, manusia disebut sebagai makhluk yang selalu didorong keingintahuan terhadap segala sesuatu. Dorongan tersebut membawa manusia untuk berfikir, menelaah dan menganalisis terhadap realitas yang dihadapinya untuk diungkapkan dan dideskripsikan agar memperoleh pengetahuan dan pemahaman secara utuh dengan harapan agar segala sesuatu yang ada dapat memberikan manfaat dalam kehidupannya (Rosita Baiti dan Abdurrazzaq, 1017).

Filsafat tidak hanya cukup diketahui, tetapi harus dipraktekkan dalam hidup sehari-sehari. Orang mengharapkan bahwa filsafat dapat memberikan kepadanya dasar-dasar pengetahuan, yang dibutuhkan untuk hidup secara baik. Filsafat harus mengajar manusia, bagaimana harus hidup secara baik. Filsafat harus mengajar manusia, bagaimana harus hidup agar dapat menjadi manusia yang baik dan bahagia. Hakikat filsafat yaitu hasrat yang menggebu-gebu atau keinginan yang sungguh-sungguh dan kemauan yang keras untuk mencari kebenaran sejati. Filsafat merupakan hal mendasar yang pada dasarnya dimiliki oleh setiap manusia. Setiap manusia baik yang tergolong pelajar bahkan yang tergolong awam sekalipun, memiliki kemampuan untuk berpikir mengenai hal-hal di sekitarnya. Bagi manusia, berfilsafat itu berarti mengatur hidup seinsaf-insafnya, senetral-netralnya dengan perasaan tanggung jawab, yakni tanggung jawab terhadap dasar hidup yang sedalam-dalamnya, baik Tuhan, alam ataupun kebenaran. 
Menarik untuk dicermati bahwa pemberian hakikat terhadap filsafat oleh kalangan filsuf dari masa ke masa cenderung mengalami perubahan-perubahan atau pergeseran dari makna hakikat yang lebih luas ke makna hakikat yang lebih sempit. Fenomenanya bahwa: pertama, mula-mula makna hakikat filsafat yang terungkap dari pendapat Phytagoras adalah mencintai kebijaksanaan (yang dibagi dalam tiga tingkatan pecinta yaitu pencinta kebijaksanaan, pencinta keberhasilan, pecinta kesenangan - keindahan); kedua, para filsuf seperti Socrates, Plato, Aristoteles, Francis Bacon, Immanuel Kant, Marcus Tullius Cicero, Johan Golitch Fickte dan Paul Nartorp memaknai filsafat sebagai master (dengan sebutan seperti induk agung, ibu, pokok pangkal) dari ilmu-ilmu dan pengetahuan serta seni. Ketiga, kalangan filsuf tersebut dan sesudahnya (seperti Plato, Aristoteles, Marcus Tullius Cicero, Al Farabi, Ibnu Rusyd, Rene Descartes dan lainnya) mempersempit makna hakikat filsafat yakni sebagai ilmu pengetahuan tentang kebenaran yang hakiki ataupun sebagai metode penyelidikan atau pemikiran dengan akal budi, atau pencarian kebenaran mengenai hakikat alam, sesuatu dan segala yang ada. Keempat, dalam perkembangan berikutnya, makna hakikat filsafat bergeser kepada dimensi proses (usaha; ikhtiar; sikap; hasil; akal; refleksi rasional; eksplisit; aktivitas; proses berfikir secara radikal; kritis; serius; mendalam; bebas; dan sistematis untuk bertanya, mengkaji, mencari, menjajaki, merenung dan menemukan hakikat kebenaran sesuatu); kelima, muncul pemaknaan yang lebih sempit seperti keinsyafan, pandangan, pengungkap dan lainnya (Ilyas, 2018).

Selanjutnya filosofi dari filsafat adalah berfikir, yaitu berfikir dengan menggunakan disiplin berfikir yang tinggi, berfikir secara sistematis, menyusun suatu skema konsepsional dan menyeluruh. Selain itu filsafat juga merupakan konsep berfikir reflektif dan kritis, serta interpretasi atau evaluasi terhadap sesuatu yang penting atau apa yang berarti dalam kehidupan. Filsafat adalah hasil daya upaya manusia dengan akal budinya untuk memahami atau mendalami secara radikal dan integral serta sistematis hakikat yang ada, yaitu: hakikat Tuhan, hakikat alam semesta dan hakikat manusia serta sikap manusia sebagai konsekuensi dari paham tersebut. Manusia yang berpikir tentang inti sari, esensi dan substansi atau berpikir hakikat sesuatu yang ada, berarti manusia itu telah keluar dari bingkai lingkaran atau batas penjelajahan ilmu (science), dan telah menginjakkan kakinya di lingkaran dunia filsafat, dunia cinta kebijaksanaan (Rosichin Mansur, 1017). 


\subsection{Konsep dan Teori Lahirnya Filsafat}

Kisah transisi dan demokratisasi kefilsafatan bermula di Yunani pada zaman Yunani kuno, yang pertama-tama mencoba untuk menerangkan dunia dengan kejadian-kejadian yang menyertainya secara mitologis. Pendekatan mitologi dipergunakan untuk menerangkan dan menyusun berbagai fenomena alam secara sistematis dan menyeluruh guna mencari dan menghubungkan antara satu mite (mitos) dengan mite lainnya. Seiring perjalanan waktu, kesusastraan Yunani mengalami perkembangan, dan ilmu pengetahuan dari Babilonia dan Mesir pun memasuki pemikiran-pemikiran masyarakat Yunani, dan hal itu ternyata menjadi titik balik terhadap pudarnya kepercayaan tentang kebenaran yang diberikan oleh pemikiran keagamaan (agama yang berlaku saat itu bukan agama samawi tetapi agama buatan manusia). Dan peran mitos-mitologi pun secara berangsur-angsur mulai hilang dan berganti dengan peran logos (rasio atau ilmu).

Lahirnya peran logos (rasio atau ilmu) pada zaman Yunani kuno semakin memberikan keleluasaan bagi para filsuf dalam mengemukakan pandangan tentang alam semesta melalui metode berfikir secara ilmiah. Penggunaan metode ini mendorong terjadinya demokratisasi berfikir kefilsafatan yaitu para filsuf bebas mengaktualisasikan bagaimana model berfikir sendiri, bebas memikirkan segala sesuatu yang ada dibalik keragaman kejadian dan fenomena yang diamati secara umum. Transisi metode berfikir dan demokratisasi berfikir kefilsafatan tersebut mengisyaratkan munculnya kesadaran para filsuf untuk mendekati problem dan kejadian alam semesta secara logis dan rasional sehingga terbuka kemungkinan-kemungkinan bagi pertanyaan lain dan penilaian serta kritik dalam memahami alam semesta. Semangat pendekatan berfikir ilmiah itulah yang memunculkan para filsuf pada zaman Yunani dimana filsafat dan ilmu pun saling berintegrasi dan bersatu (Natasya Virginia Leuwol et al., 2020).

Meskipun filsafat merupakan bagian dari transmisi ilmu dari Yunani yang menyebar ke berbagai pelosok dunia sejak dari 500 tahun SM, tetapi berfilsafat bukan hak monopoli mereka saja. Orang India, Mesir dan Irak justru telah mengembangkan suatu peradaban yang jauh lebih maju dan tinggi dari Yunani. Hal ini bisa dilihat dari adanya pengaruh al-Hikmah Mesir Kuno 
2 Bahwa manusia adalah makhluk biologis dan social;

3 Bahwa nilai-nilai bersifat relatif;

4 Bahwa berpikir kritis secara cerdas adalah esensial. 


\section{Daftar Pustaka}

Abdul Karim, 2014. Sejarah Perkembangan Ilmu Pengetahuan, Jurnal Fikrah, Volume 2 Nomor 1

Abdullah, Abdul Rahman Haji, 2005. Wacana Falsafah Ilmu: Analisis Konsep-Konsep Asas dan Falsafah Pendidikan Negara. Utusan Publications \& Distributors SDN BHD

Abuddin Nata, 2008. Manajemen Pendidikan, Jakata: Kencana

Achmadi, Asmoro. 2003. Filsafat Umum. Jakarta: RajaGrafindo Persada.

Adian Husaini et.al, 2013. Filsafat Ilmu: Perspektif Barat dan Islam. Penerbit Gema Insani, Jakartta

Adian Husaini, 2005. Wajah Peradaban Barat: Dari Hegemoni Kristen ke Dominasi Sekuler- Liberal. Gema Insani, Jakarta.

Adib, Mohammad. 2015. Filsafat Ilmu; Ontologi, Enpistemologi, Aksiologi, dan Logika Ilmu Pengetahuan. Yogyakarta: Pustaka Belajar

Aditama, A. Munir Mulkhan, 1994. Paradigma Intelektual Muslim: Pengantar Filsafat Pendidikan Islam \& Dakwah, Yogyakarta: SIPress Tulisendw.blogspot.com/2010/02/epistemologi.html

Admin Armas dan Dinar Dewi Kania 2013. Sekularisasi Ilmu, dalam Adian Husaini (et.al.),

Afiq Fikri Almas, 2018. Sumbangan Paradigma Thomas S. Kuhn dalam Ilmu Dan Pendidikan (Penerapan Metode Problem Based Learning dan Discovery Learning), Jurnal At Tarbani, 3(1): 89-106 
Agus Kamaludin, 2008. Makna, Kebenaran, Dan Cara Memperoleh Kebenaran". Jurusan Pendidikan Sains Program Pasca Sarjana Universitas Negeri Yogyakarta

Ahmad Fuad Basya, 2015. Sumbangan Keilmuan Islam pada Dunia. (Terjemahan), Penerbit Pustaka Al-Kautsar, Jakarta.

Ahmadi, Asmoro. 2013. Filsafat umum. Jakarta: Rajawali Pers, Amiere.multiply.com/journal/item/19/Metode_Ilmiah

Al-Faruqi, 1991. Pengislaman Ilmu (terjemahan). Penerbit Dewan Bahasa dan Pustaka, Kuala Lumpur.

Almas, Afiq Figri, 2018. Sumbangan Paradigma Thomas S. Kuhn Dalam Ilmu Dan Pendidikan (Penerapan Metode Problem Based Learning Dan Discovery Learning), Jurnal At-Tarbani, Volume 3(1); 98-106

Amsal Bakhtiar, 2004. Fisafat Ilmu, Jakarta: Grafindo Persada, hal. 5

Ann, Mary, 2011. Kuhn's Scientific Revolutions and Paradigma Shifts: A Social Science Model of Anomalies and Revolutions in the Clerical Hierarchy of the Catholic Church. Academic Journal Article from Magistra, Vol.11, No.2

Anwar, Saeful. 2007. Filsafat Ilmu Al-Ghazali; Dimensi Ontologi, dan Aksiologi, Bandung: Pustaka Setia.

Atkinson, Sam, 2011. The Philosophy Book: Big Ideas Simply Explained. London: Dorling Kindersley Limited

Badri Yatim, 1993. Sejarah Peradaban Islam. PT RajaGrafindo Persada, Yogyakarta.

Bagir, H., 2005. Buku Saku Filsafat Islam. Available at: https://books.google.co.id/books?id=YZ3fvTCymQgC

Bahar, H. M., \& Teng, A. 2017. Filsafat Kebudayaan Dan Sastra (Dalam Perspektif Sejarah). 5, nomor 1, 2354-7294.

Baharuddin Ahmad, (994. Falsafah Sains daripada Perspektif Islam. Dewan Bahasa

Bahrum, 2013. Ontologi, Epistemologi Dan Aksiologi, Jurnal Sulesana, Volume 8 Nomor 2 
Baldwin, Thomas (ed.)., 2008. The Cambridge History of Philosophy 18701945. Cambridge University Press

Bird, Alexander, 2011. Stanford Encyclopedia of Philosophy: Thomas Kuhn. www.plato.stanford.edu/entries/thomas-kuhn/\#5

Burhanuddin Salam, 2000. Sejarah Filafat Ilmu dan Teknologi. Penerbit Rineka Cipta. Jakarta

Darwis A. Soelaiman, 2002. Filsafat: Barat, Islam, dan Pancasila. Penerbit Universitas Syiah Kuala, Banda Aceh

Fikri, M., 2018. Rasionalisme Descartes dan Implikasinya Terhadap Pemikiran Pembaharuan Islam Muhammad Abduh', TARBAWI: Jurnal Pendidikan Agama Islam, 3(02), pp. 128-144. doi: 10.26618/jtw.v3i02.1598

Haikal, Husain, 2015. Mencari Jati Diri? (Relasi antara Nasionalisme dengan Pendidikan). Khazanah Pendidikan, Volume 2(2).

Hakim, Lukman, 2012. Prinsip-prinsip Ekonomi Islam." Jakarta: Eirlangga

Hamka, Rusydi 1981. Pribadi dan Martabat Buya Prof. DR. Hamka. Jakarta. Pustaka Panjimas

Hanafi, A., 1976. Pengantar Filsafat Ilmu. Jakarta: Bulan Bintang.

Haninah. 2001. Agama Pragmatis. T.t.: Indonesia Tera.

Haq, Hamka, 2011. Pancasila 1 Juni dan Syariat Islam, Jakarta: PT. Wahana Semesta Intermedia

Haqi, Ahmad Hamdani, 2013. Nasionalisme Bung Karno dalam perspektif pendidikan Islam, Thesis. IAIN Walisongo.

Hardiman, Budi F., 2004. Filsafat Modern. Jakarta: Gramedia

Hariyono, Hariyono 2012. Pola Demokrasi Yang Dikembangkan Pendiri Bangsa. Paramita: Historical Studies Journal, Volume 22(2)

Hasan, Ismail 1988. Studi Tentang Sarekat Islam Merah: Tinjauan Historis. Thesis. UIN Sunan Ampel Surabaya. Hasibuan, Sofia Rangkuti 1999. Individualisme berkemandirian dalam Sejarah Amerika

Herimanto, and Winarno, 2016. Ilmu Sosial \& Budaya Dasar. Jakarta: Bumi Aksara, 2016, vol. 10 
https://mujigunarto.wordpress.com/2017/10/09/aliran-filsafat-empirisme/

Huene, Paul Hoyningen, 1998. On Thomas Kuhn's Philosophical Significance.

www.muse.jhu.edu/journals/configurations/summary/v006/6.1hoynin gen-uene.html

Hunnex, Milton D., 2004. Peta filsafat: Pendekatan Kronoligis dan Tematik. Jakarta: Teraju

Ilyas, 2018. Pengantar Filsafat, Cetakan ketiga, Makassar: Nas Media Pustaka, hal 48

Iqbal, Muhammad, and Azhari Akmal Tarigan, 2004. Syariat Islam di Indonesia: aktualisasi ajaran dalam dimensi ekonomi, politik, dan hukum. Kerja sama Fakultas Syariah, IAIN Sumatra Utara dengan Penerbit Misaka Galiza

Ismail, N., Aisyah, S. and Bakri, W., 2020. Rasionalisme dalam Perkembangan Ekonomi Mainstrim dan Islam di Indonesia', Ijtihad: Jurnal Hukum dan Ekonomi Islam, Volume 14(1), pp. 65-80. Available at: http://eprints.uwe.ac.uk/11735/2/

Jalal, Abd Fattah, 1987. Min al-Tarbiyah Fi al-Islam, Diterjemahkan oleh Hery Noer Aly dengan Judul Azas-azas Pendidikan Islam, Cet. I: Jakarta.

Jalaluddin dan Abdullah, 1997. Filsafat Pendidikan. Jakarta: Gaya Media Pratama.

Johari Rugani. 2020. Konsep Pemikiran Pendidikan Kebangsaan Haji Oemar Said Cokroaminoto Dalam Perspektif Pendidikan Islam, Penerbit. Tohar Media, Makassar

Jujun S. Sumantri, 2005. Filsafat Ilmu: Sebuah Pengantar Populer. Jakarta: Sinar Harapan

Kees Bertens, 1995. Ringkasan Sejarah Filsafat, Edisi Revisi, cetakan ke 13, Yogyakarta: Kanisius.

Kirom, Sazalil, et al. 2013. Buruh Dan Kekuasaan: Dinamika Perkembangan Gerakan Serikat Pekerja Di Indonesia (Masa Kolonial-Orde Lama). Jurnal Mahasiswa Teknologi Pendidikan, volume 1(1)

Kohar, Abdul, 2012. Pendidikan Agama Berbasis Multikulturalisme (Studi Kritis). Jurnal AT TA'DIB, Volume 7(2) 
Kuhn, Thomas S. 1970. The Structure of Scientific Revolutions, second edition enlarged. Chicago: The University of Chicago Press

Kuntjojo, 2009. Filsafat Ilmu,.Program Studi Pendidikan Bimbingan Dan Konseling Universitas Nusantara Pgri Kediri, http://dc112.4shared.com/doc/ID2XZxA7/preview.html

Kurniawan, Syamsul, and Erwin Mahrus. 2011. Jejak pemikiran tokoh pendidikan Islam: Ibnu Sina, Al-Ghazali, Ibn Khaldun, Muhammad Abduh, Muhammad Iqbal, Hassan al-Banna, Syed Muhammad Naquib al-Attas, KH Ahmad Dahlan, KH Hasyim Asy'ari, Hamka, Basiuni Imran, Hasan Langgulung, Azyumardi Azra. Ar-ruzz Media

M. Siti Ritaudin, 2015. Mengenal Filsafat dan Karakteristiknya, Kalam, Jurnal Studi Agama dan Pemikiran Islam, Volume 9 Nomor 1, hal 127.

Mahawati, E. et al. 2021. Keselamatan Kerja dan Kesehatan Lingkungan Industri, Yayasan Kita Menuli. Edited by R. Watrianthos and Janner Simarmata. Medan.

Maimun, 2015. Seyyed Hossein Nasr : Pergulatan Sains dan Spiritualitas Menuju Paradigma Kosmologi Alternatif. Penerbit IRCiSoD, Yogyakarta.

Mano, K., 2012. Makalah Filsafat Rasionalisme', p. 1. Available at: http://maulana-ikbar.blogspot.co.id/2012/05/makalah-filsafatrasionalisme.html

Marzuki, I. et al., 2020. Pengembangan Desa Cerdas Berorientasi Organik dan Teknologi Informasi. Makassar: Tohar Media.

Muchsin, 2004. Ikhtisar Materi Pokok Filsafat Hukum, cet ke-1, Surabaya: STIH'IBLAM, hal. 3.

Mudhofir, Ali, 2002. Kamus Filsuf Barat. Yogyakarta: Pustaka Pelajar. Okhasa, Samir. Philosophy of Science: A Very Short Introduction. Oxford: Oxford University Press

Muhammad Zain Hanafi, 2018. Eksistensi Filsafat Pendidikan, Jurnal Istiqra', Volume V Nomor 2

Mulyono, 2018. Buku Ajar Mata Kuliah Ilmu Sosial Budaya Dasar, pp. 1-54.

Muthahhari, M., 2011. Belajar Konsep Logika', p. 186. 
Nasoetion, Andi Hakim, 1999. Pengantar ke Filsafat Sains. PT Pustaka Utera Sntar Nusa, Bogor.

Natasya Virginia Leuwol, P. W. et al., 2020. Pengembangan Sumber Daya Manusia Perguruan Tinggi. 1st edn. Edited by J. Simarmata. Medan. Available at: https://kitamenulis.id/2020/10/07/pengembangansumber-daya-manusia-perguruan-tinggi-sebuah-konsep-fakta-dangagasan/.

Noor Amirudin, 2018. Filsafat Pendidikan Islam, cetakan pertama, Gresik: Caremedia Communication, hal 12.

Palmquis, S., 2002. Pohon filsafat. Terj. M.Shodig. Yogyakarta: Pustaka Pelajar Offset

Purba, B. et al., 2020. Ekonomu Sumber Daya Alam. Edited by J. Simarmata. Medan: Yayasan Kita Menulis. Available at: https://kitamenulis.id/2020/10/08/ekonomi-sumber-daya-alamsebuah-konsep-fakta-dan-gagasan/.

Purba, P. B. et al., 2020. Dasar-dasar Manajemen Pendidikan. Edited by R. Wattrianthos. Meda: Yayasan Kita Menulis. Available at: https://kitamenulis.id/2020/12/14/dasar-dasar-manajamenpendidikan/.

Rachmawati, F. 2020. Kritik terhadap Konsep Ideologi Komunisme Karl Marx. Jurnal Sosiologi Agama Indonesia (JSAI), 1(1), 66-78. https://doi.org/10.22373/jsai.v1i1.424

Raja Lottung Siregar, 2016. Teori Belajar Perenialisme, Jurnal Al Hikmah, Volume 13 Nomor 2.

Rapar, Jan Hendrik. 1996. Pengantar Filsafat. Yogyakarta: Kanisius

Redja Mudyahardjo, 2002. Filsafat Ilmu Pendidikan Suatu Pengantar, Bandung: PT. Remaja Rosdakarya. Cet. II

Riyadi, A. and Sukma, H. V., 2019. Konsep Rasionalisme Rene Descartes Dan Relevasinya Dalam Pengembangan Ilmu Dakwah', An-Nida: Jurnal Komunikasi Islam, 11(2). doi: 10.34001/an.v11i2.1026.

Rosichin Mansur, 2017. Filsafat Ilmu Filsafat Idola Masa Depan, Jurnal Al Ghazwah, Volume 1 Nomor 1 
Rosita Baiti dan Abdur Razzaq, 2017. Esensi Wahyu dan Ilmu Pengetahuan, Jurnal Wardah, Volume 18 Nomor 2, hal 1.

Soliha, E. 2013. Keterkaitan Teori Dan Riset Empiris: Suatu Pendekatan Theory-Setting-Testable Hypothesis Model. Jurnal Performance, 14(2), 35-47.

Sri Rahayu Wilujeng, 2014. Ilmu dalam Perspektif Filsafat, Jurnal Humanika, Volume 20 Nomor 2, hal 1.

Sudarmanto, E. et al., 2020. Konsep Dasar Pengabdian Kepada Masyarakat; Pembangunan dan Pemberdayaan. Edited by A. Karim and J. Simarmata. Medan: Yayasan Kita Menulis. Available at: https://kitamenulis.id/2020/12/22/konsep-dasar-pengabdian-kepadamasyarakat-pembangunan-dan-pemberdayaan/.

Sumantri, M. S. 2015. Modul Hakikat Manusia dan Pendidikan', pp. 1-43.

Supriasumantri, Jujun S., 1985. Filsafat Ilmu sebuah Pengantar Populer. Jakarta: Sinar Harapan

Surajiyo and Sriyono, 2017. Sikap Ilmiah Ilmuwan', Prosiding Diskusi Panel Pendidikan, Menjadi Guru Pembelajar, Keluarga Alumni Universitas Indraprasta PGRI, (April), pp. 12-22.

Surajiyo. 2018. Keunggulan Dan Ketangguhan Ideologi Pancasila. Universitas Inrdaprasta PGRI

Suriasumantri, Jujun S. (ed). 2003. Ilmu Dalam Perspektif (sebuah kumpulan krangan tentang hakikat ilmu). Jakarta: Yayasan Obor Indonesia.

Suriasumantri, Jujun. 2009. Filsafat Ilmu: Sebuah Pengantar Populer. Pustaka Sinar Harapan, Jakarta.

Susono, M., 2018. Menalar Tuhan', Kanisus

Sutardjo A.Wiramihardja, 2006. Pengantar Filsafat, Bandung: PT. Refika

Sutisna, I. et al., 2017. Relasional Ilmu Filsafat Dengan Pendidikan

Syafrizal et al., 2021. Pengantar Ilmu Sosial, Yayasan Kita Menulis. Edited by R. Watrianthos. Medan: Yayasan Kita Menulis

Syarieeati, Ali 1989. Membangun Masa Depan Islam. (Terj.). Penerbit Mizan. Bandung 
Toenlioe, Anselmus JE. 2016. Teori dan Filsafat Pendidikan. Malang: Gunung Samudra

Uyoh Sadulloh, 2007. Pengantar Filsafat Pendidikan, Bandung: Penerbit Alfabeta

Wahyuddin, Z. 2020. Refleksi Keterhubungan Filsafat Ilmu. 2(1), 49-54.

Zulkarnaenfajar.blogspot.com/2011/10/25/epistemologi-ilmupengetahuan.html 


\section{Biodata Penulis}

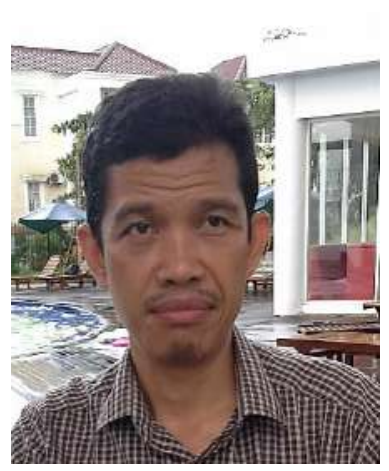

Dr. Ismail Marzuki, M.Si, lahir di Kabere, 03 Juli 1973. Pendidikan formal yang telah diikuti SD Negeri 19 Kabere Tahun 1980-1986, SMP Negeri Kabere Tahun 1986-1989, dan SMA Negeri 1 Enrekang 1989-1992. Gelar sarjana Sains (kimia) disandang tahun 1999, di Jurusan Kimia F.MIPA UNHAS, dan gelar Magister Sains (M.Si) Tahun 2003. Menyelesaikan program Doktor tahun 2016, Program Pascasarjana UNHAS.

Karir sebagai akademisi dimulai tahun 2000 hingga sekarang. Status PNS (Dosen) diperoleh pada Tahun 2005, pada unit kerja Kopertis (L2dikti) wil. IX Sulawesi. Jabatan struktural yang pernah di sandang, yakni: Direktur Akademi Analis Kimia Yapika Makassar, (Tahun 2002-2008), Ketua I Bidang Akademik Sekolah Tinggi Ilmu Kesehatan (STIKES) Yapika Makassar (Tahun 2008-2012). Ketua Stikes Bina Mandiri Gorontalo (Tahun 2014-2015), Dimutasi ke Universitas Fajar (UNIFA), Tahun 2015, pada Prodi home base Teknik Kimia. Tugas tambahan yang diamanahkan oleh UNIFA adalah Pimred Jurnal Techno Entrepreneur Acta (2016-sekarang), Ketua Unit Pusat Karir UNIFA (Tahun 2016-2018) dan Ketua Lembaga Penjaminan Mutu Internal UNIFA, (2019-2020), serta Dekan Fak. Pascasarjana Univ. Fajar, (2020-sekarang). Sejak pandemic coviv-19 dan masa pemulihan dengan kebiasaan hidup baru bergabungan dalam komunitas Yayasan Kita Menulis, yang hingga saat ini telah menulis 20 book chapter dan 3 tahun terakhir sebagai dosen pengajar filsafat pada Program S2 Universitas Fajar. 


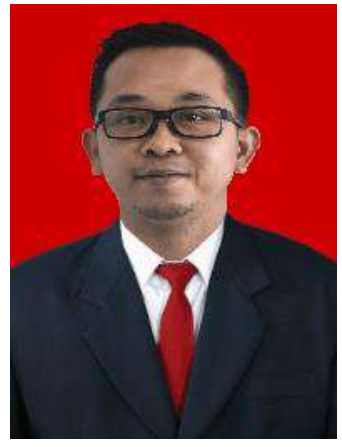

Siswandy, S.Kom., lahir di Maros pada tanggal 9 April 1987. Telah menempuh Pendidikan formal, yaitu pada SD Negeri No. 10 Sanggalea Kabupaten Maros pada Tahun 1993 - 1999, SMP Negeri 1 Maros pada Tahun 1999 - 2002, dan SMA Negeri 1 Maros pada Tahun 2002 - 2005. Gelar Sarjana Komputer (S.Kom.) diraih pada STMIK Dipanegara Makassar Tahun 2010 dengan Jurusan Teknik Informatika. Saat ini sedang menempuh Pendidikan S2 dengan Program Studi Magister Rekayasa Infrastruktur dan Lingkungan (MRIL) Fakultas Pascasarjana, Universitas Fajar Makassar sejak Tahun 2020 hingga sekarang.

Berprofesi sebagai Pegawai Negeri Sipil (PNS) pada Kementerian Pekerjaan Umum dan Perumahan Rakyat sejak Tahun 2010 hingga sekarang. Meniti karir sebagai PNS dimulai sebagai staff pada Direktorat Pengembangan Penyehatan Lingkungan Permukiman, Direktorat Jenderal Cipta Karya sejak Tahun 2010 - 2015. Selanjutnya pada Tahun 2015 menerima SK Mutasi dan ditempatkan pada Satuan Kerja Pengembangan Sistem Penyehatan Lingkungan Permukiman (Satker PSPLP) Provinsi Kalimantan Utara, yang telah berganti nama menjadi Balai Prasarana Permukiman Wilayah (BPPW) Kalimantan Utara.

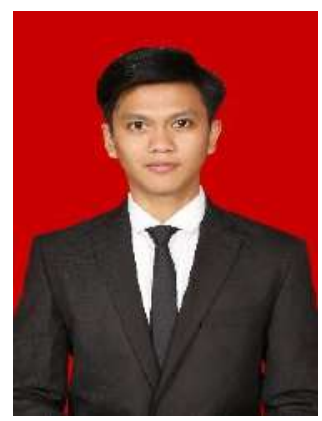

M. Iqbal, ST., lahir di Ammani, 28 Maret 1998. Pendidikan formal yang telah diikuti SD Negeri 207 Ammani Selatan 2004-2010, SMP Negeri 2 Cempa Tahun 2010-2013, dan SMK Negeri 1 Pinrang 20132016. Gelar sarjana Teknik disandang tahun 2020, di Jurusan Teknik Sipil Fakultas Teknik Universitas Fajar Makassar. 


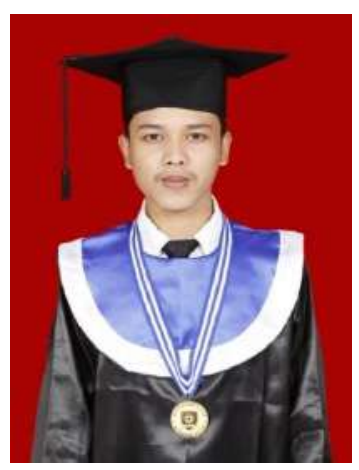

Andi Muhammad Reza, ST. lahir di Anabanua, 12 Februari 1996. Pendidikan formal yang telah diikuti Sekolah Dasar Negeri 273 Anabanua Tahun 20022008, Sekolah Menengah Pertama Negeri 1 Maniangpajo Tahun 2008-2011, dan Sekolah Menengah Atas Negeri 1 Maniangpajo 2011-2014. Gelar sarjana Teknik disandang tahun 2019, di Jurusan Teknik Mesin Fakultas Teknik UNIFA, sekarang sedang melanjutkan kuliah Magister Rekayasa Infrastruktur dan Lingkungan di Fakultas Pascasarjana UNIFA. Pengalaman Organisasi semasa kuliah S1 , Badan Eksekutif Himpunan Mahasiswa Mesin Fakultas Teknik Universitas Fajar 2016-2018, Himpunan Pelajar Mahasiswa Wajo Komisariat Gilireng 2015-2017.

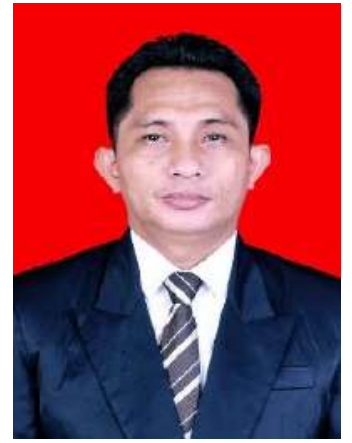

Ir. I Putu Artawan, ST., lahir di Kendari, 26 Mei 1980. Pendidikan formal yang telah diikuti SD Negeri Tridana Mulya Tahun 1986-1992, SMP Negeri 2 Kendari Tahun 1992-1995, dan SMA Negeri 1 Kendari 1995-1998. Gelar sarjana Teknik disandang tahun 2005, di Jurusan Teknik Sipil Fakultas Teknik Universitas 45 Makassar, menyelesaikan Pendidikan profesi Insinyur di Fakultas Teknik Universitas Hasanuddin tahun 2020. Saat ini melanjutkan studi pada program strata dua program studi Rekayasa Infrastruktur dan Lingkungan Universitas Fajar Makassar. 


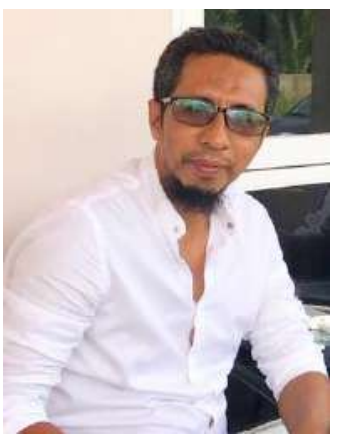

Arsad Ely, ST, lahir di Ambon-Assilulu, 05 Juli 1974. Pendidikan formal yang telah diikuti SD Negeri Assilulu Tahun 1981-1987, SMP Negeri 1 Ambon Tahun 1987-1990, dan SMA Muhammdaiyah 1990-1993. Gelar sarjana Teknik Sipil Universitas Muslim Indonesia disandang tahun 1999. Karir sebagai Konsultan Pengawas-Perencana dimulai tahun 1999 hingaa saat ini.

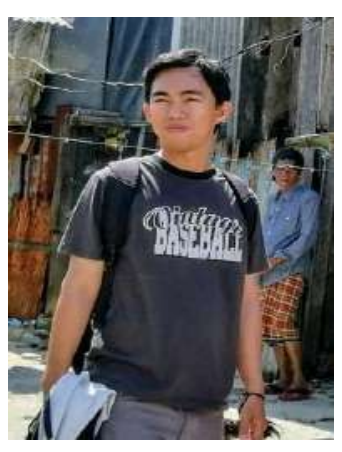

Irfan Saputra, Lahir di Takalar, 03 Mei 1988. Pendidikan formal yang telah di ikuti SDN Centre Mangadu-Takalar Tahun 1994-2000, SMPN 1 Mangarabombang-Takalar tahun 20002003, SMKN 2 Makassar tahun 2003-2006, Gelar Ahli Madya tahun 2010, di Jurusan Teknik Elektronika Fakultas Teknik Universitas Negeri Makassar, Gelar Sarjana tahun 2013, di Jurusan Teknik Informatika Fakultas Teknik Universitas Satria Makassar, Gelar Magister tahun 2015 di Jurusan Magister Ilmu Hukum Universitas Indonesia Timur dan sedang menempuh study pada program study Magister Rekayasa Infrastruktur dan Lingkungan Fakultas Pascasarjana UNIFA Makassar tahun 2020 hingga Sekarang. Karir Sebagai guru tahun 2010-2017 dan Tenaga Fasilitator Lapangan dari tahun 2017-2018. 


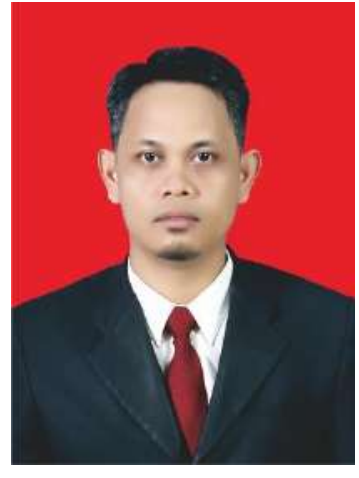

Ir. Musmuliyadi ST, IPM, Tempat/ Tanggal Lahir: Benteng, 21 Oktober 1975, Domisili saat ini di Komp. Taman Telkomas Jl. Telepon 2 No. 110A Makassar. Riwayat Pendidikan Strata satu Fakultas Teknik Jurusan Teknik Arsitektur UMI Makassar, Tahun 2002, Program Profesi Insinyur, Fak. Teknologi Industri, UMI Makassar, 2019 dan saat ini sedang mengikuti program magister pada Program Studi Rekayasa Infrastruktur dan Lingkungan di Fakultas Pascasarjana Universitas Fajar. 


\section{Sinopsis}

Setiap karya yang disusun atas landasan perencanaan dan penyusunan yang matang dapat memperoleh hasil yang baik. Penyusunan tersebut tentunya memiliki filosofi tersendiri yang berbeda dengan yang lain. Karya Filsafat Ilmu Pengetahuan tentu sudah sangat banyak dan tersebar luas di banyak kalangan, meskipun demikian, buku ini tetap mempunyai nilai filosofis yang memilikinya dengan berbagai makna berbeda dengan karya sejenis, minimal pada aspek ruang dan waktu dalam rencana dan penyusunannya. Buku ini terdiri atas $8 \mathrm{Bab}$ dengan rincian:

Bab I Potret Filsafat Dulu dan Kini;

Bab II Pandangan Ilmu Pngetahuan Terhadap Filsafat;

Bab III Pandangan Filsafat terhadap Fenomena Alam;

Bab IV Eksistensi Manusia sebagai Pencetus Ilmu;

Bab V Pandangan Filsafat terhadap Pendidikan Kebangsaan Berbasis Tauhid;

Bab VI Pandangan Filsafat dalam Rasionalisme Manusia;

Bab VII Filsafat dan Paradigma Sains Masa KiniTeori dan Nilai dalam Filsafat;

Bab VIII Ilmu Pengetahuan, Teori dan Nilai dalam Filsafat

Pilihan materi dalam setiap Bab yang disajikan merupakan topik-topik yang dipandang sebagai bagian yang berperan dalam merunut kembali perkembangan ilmu pengetahuan dulu dan kini. Buku ini berusaha untuk menyambungkan kembali alur pengetahuan yang dianggap renggang akibat munculnya era globalisasi yang di barengi dengan model kehidupan yang begitu renggang atas masa dan kehidupan kini dengan masa lampau. 


\section{SINOPSIS}

Setiap karya yang disusun atas landasan perencanaan dan penyusunan yang matang dapat memperoleh hasil yang baik. Penyusunan tersebut tentunya memiliki filosofi tersendiri yang berbeda dengan yang lain. Karya Filsafat limu Pengetahuan tentu sudah sangat banyak dan tersebar luas di banyak kalangan, meskipun demikian, buku ini tetap mempunyal nilai filosofis yang memillikimya dengan berbagai makna berbeda dengan karya sejenis, minimal pada aspek ruang dan waktu dalam rencana dan perwusunannya. Buku initerdiriatas 8 Bab dengan rinclan:

Babl PotretFilsafatDuludan Kinis

Babll Pandanganilmu Prgetahuan Terhadap Filsafat;

Babill PandanganFilsafat terhadap Fenomena Alam;

BabiV EksistensiManusia sebsgai Pencetus limu;

BabV PandanganFilsafat terhadap Pendidlikan Kebangsaan Berbasis Tauhid;

BabVI Pandanganfilsafat dalam Rasionalisme Manusia;

BabVII Filsafat dan Paradigma Sains Masa Kinifeori dan Nilai dalam Filsafat;

Bab Vil Ilmu Pengetahuan, Teori dan Nilai dalam Filsafat

Pilihan materi dalam setiap Bab yang disajikan merupakan topik-topik yang dipandang sebagai bagian yang berperan dalam merunut kembali perkembangan ilmu pengetahuan dulu dan kini. Buku ini berusaha untuk menyambungkan kembali alur pengetahuan yang dianggap renggang akibat munculnya era globalisasi yang di barengi dengan model kehidupan yang begitu renggang atas masa dan kehidupan kini dengan masa lampau. 